\title{
Digitalization influence on shopping centers strategic management
}

\author{
Irene Mihaela IONIŢĂ \\ The Bucharest University of Economic Studies, Bucharest, Romania \\ iionita@sonerg.info.ro
}

\begin{abstract}
Shopping centers are an important aspect of the extremely dynamic life of the $21^{\text {st }}$ century consumer. Nowadays, worldwide, shopping centers represent significant multimillion euro investments, remarking themselves with bold architectures and structures and an individual brand image. Retail markets are currently under transformation by a confluence of new retailing technologies, dramatic shifts in the demographic profile and preferences of more affluent and educated shoppers. Part of the market share in modern retail moved to new forms of selling, which weakened the offer of some traditional retailers, while also creating opportunities for retailers to move and integrate their offerings with new digital tools (via electronic commerce, social commerce and mobile commerce). Meeting customer needs and increasing sales are the primary drivers behind retailers use of information systems and technology (IS/IT). New developments in IS/IT offer new opportunities and challenges for organizations and society. The current paper proposes to analyze the way digital media and information technology (computers and mobile devices) influences the virtual and physical shopping experiences, and shopping centers management consequently. The need for communication \& sales channels integration, the impact of new information technologies (IT's), the growing role of social / digital media, the balance between personalization and privacy - all represent challenges retail industry needs to currently adapt to face digitalization. E-commerce is transforming both consumer behavior and retailing business models, by greatly expanding shopping convenience, selection and affordability.
\end{abstract}

Keywords: e-business, digital challenge, technology change, shopping centers, management.

\section{Introduction}

Retail markets are currently under transformation by a confluence of new retailing technologies, dramatic shifts in the demographic profile and preferences of more affluent and educated shoppers.

Every 50 years or so, shopping industry undergoes a major change (Rigby, 2011).

- A century and a half ago, the growth of big cities and the rise of railroad networks made possible the modern department store.

- Mass-produced automobiles came along 50 years later, and soon shopping malls lined with specialty retailers were dotting the newly forming suburbs and challenging the city-based department stores.

- The 1960s and 1970s saw the spread of discount chains. Walmart, Kmart, and the like-and, soon after, big-box "category killers" such as Home Depot, all of them undermining or transforming the old-style mall.

Each wave of change doesn't eliminate what came before it, but it reshapes the landscape and redefines consumer expectations, often beyond recognition. Shopping industry either adapt or die out, as the new wave takes volume from their stores and make the remaining volume less profitable (Rigby, 2011).

Nowadays, in the retail sector today, consumers often seek information online relating to purchases that ultimately are concluded through traditional retail channels. Millions of people worldwide use the Internet to search for information about products, and many consequently purchase these products online (Caboni \& Bruni, 2015). 
New technology, in tandem with wider structural economic and societal macro trends, has facilitated and accelerated changes to consumer buying behavior. Retailers are responding with a shift towards omni-channel business models. Shopping centre landlords and tenants are adapting to a 'new consumer' using home computers, tablets, smartphones and in-store kiosks or sales associates to research, experience and decide on a product (ICSC, 2015).

The raise of the Internet and the change in the consumer behavior have motivated classic brick-and-mortar retailers \& shopping centers to go multichannel (by adding Internet), while Internet- and catalog-based retailers have similarly added channels such as mobile phones and physical stores.

As technological progress facilitated access to services regardless of location and time of day, online shopping became more and more common, turning into a social phenomenon (Birner, 2015).

According to Caboni \& Bruni (2015), currently we already have several interconnected concepts: e-commerce (Electronic commerce), s-commerce (Social commerce) and m-commerce (Mobile commerce).

E-commerce is related to the use of electronic media like the Internet to transact retail activities.

M-commerce is particularly related to the growing number of consumers with smartphones or other Internet-capable mobile devices and can be considered an extension of e-commerce. Linked to this concept appeared the Quick Response (QR) Technology, that can connect the physical shop to the e-commerce world via mobile devices technology (implementing technologies such as bar-coding, scanning, etc.).

Social commerce (s-commerce) can be seen as a commerce activity developed through social media such as Facebook, Twitter, or other platforms. Clients today are increasingly interested in emotional involvement with retailers by sharing their own experiences and opinions on the products or services they have purchased or have the aim to purchase. Thus s-commerce merits broad consideration in conjunction with the more technical tools of e-commerce and m-commerce (Caboni \& Bruni, 2015).

As conclusion, e-technologies \& internet are more and more becoming a core section of the retail business.

\section{Literature review}

This paper is the result of bibliographical research based on industry specific virtual collections of materials (papers published in academic journals and industry official reports). The documenting steps were: review, selection, synthesizing, capitalization of the results, conclusions. The keywords used for searching the papers were electronic commerce, e-commerce, shopping centers, retail, management.

\section{New technology impact on shopping industry (shopping centers, retailers, etc.)}

Computers and mobile devices already influence the virtual and physical shopping experiences and affect how retail business and shopping centers are designed and operated, better accommodating the needs of individual shoppers to an E-business model (Benson et al., 2010).

Markets differ in their digital retail maturity in terms of the share of online and mobile shopping penetration. Internet access is a prerequisite to accessing digital shopping. While digital access has fast become regarded as a basic necessity by consumers in many countries, it is not universal (ICSC 2015). 


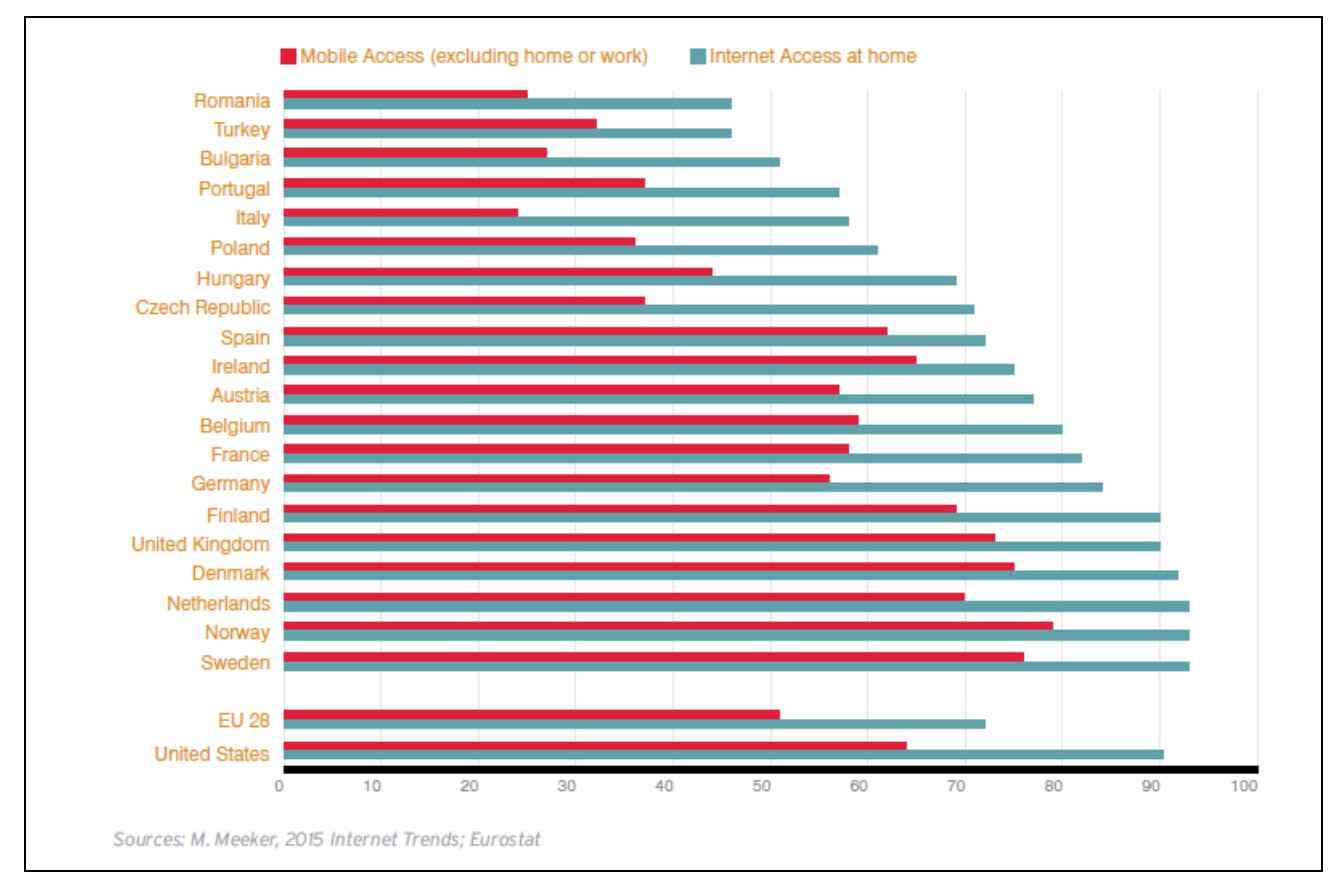

Figure 1. Home and Mobile Internet Access, 2014 (Percentage of Individuals)

Source ICSC, 2015.

Competition for online shopping is increasing, as nowadays much digital retailing is now highly profitable. Amazon's five-year average return on investment, for example, is $17 \%$, whereas traditional discount and department stores average 6.5\% (Rigby, 2011).

Total 2012 e-commerce sales in the United States amounted to US $\$ 225.3$ billion, about $16 \%$ more than 2011 . In comparison, total retail sales increased by $5 \%$ from 2011 to 2012, including much faster growth in the ecommerce category. E-commerce represented only $2.0 \%$ of total unadjusted retail sales for the fourth quarter of 2003 but grew to $6.2 \%$ by the end of 2012 (Kircher, 2013).

Amazon is by far the most important global e-commerce player at present, with second-quarter sales of US $\$ 23.18$ billion in 2015 . However, companies such as the Chinese JD.com and Alibaba, the Brazilian Saraiva, the Nigerian Jumia, and the Japanese Rakuten are regionally much more important than Amazon and growing as well (Birner, 2015).

Reflecting Internet penetration, online sales growth varies significantly across markets. The U.S., U.K. and Nordic markets have the highest online share of retail sales and also provide the most accurate data. Establishing the rate of growth and scale of Internet sales is difficult as not all markets have reliable data (ICSC , 2015). 


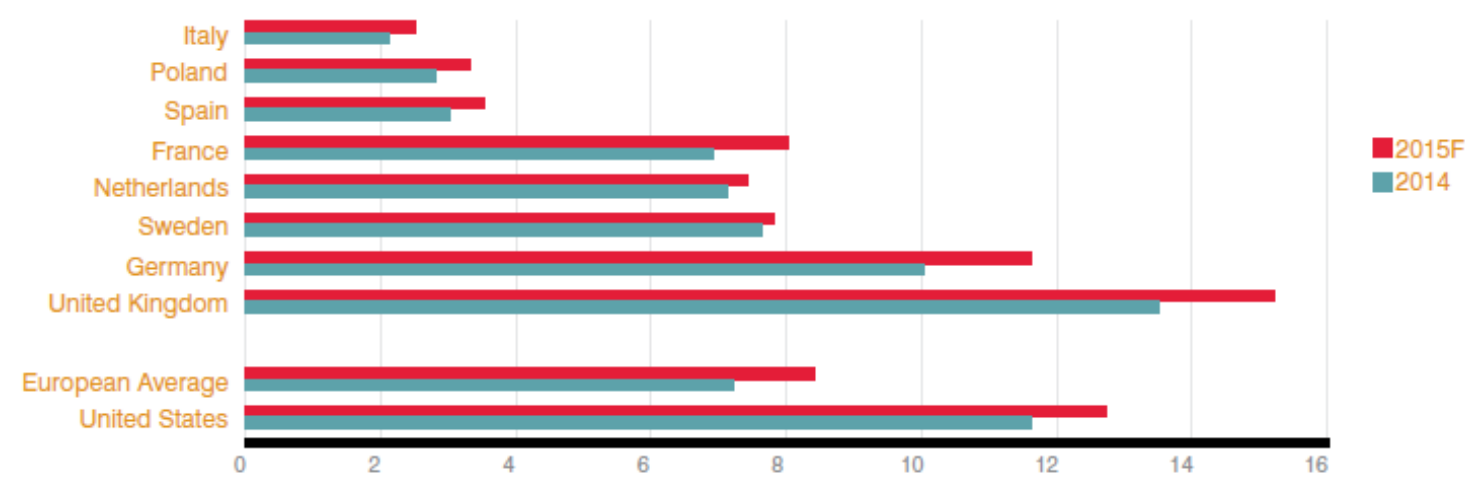

PICBE $\mid 753$

Figure 2. Online Sales as Percentage of Retail Sales*, 2014 and 2015F (retail sales exclude autos, gas, tickets, food and beverage (F\&B) services)

Source ICSC, 2015.

All these are in the detriment of classic retail spaces and shopping centers, consequently. Technological advancements are expected to decrease space demand as consumers obtain virtually anything they want online and may experience the brand outside the shopping traditional space / center (Benson et al., 2010).

Forrester Research, an American technology and market-research company, projects e-commerce sales in the United States for 2017 at $\$ 370$ billion, which would represent about $10 \%$ of total retail sales. Although approximately $90 \%$ of retail sales will still be in the traditional format, US $\$ 370$ billion in sales, at an estimated average productivity of US $\$ 400$ per sf (all retail space, not just shopping centers), is equivalent to 925 million sf of bricks-and-mortar selling space that, either may no longer be necessary, or may need to be re-deployed with other products or services, assuming no dramatic demand change (from income, population, market share, etc.) (Kircher, 2013).

The future reduction in retail space demand will induce significant new vacancies in existing centers.

This puts huge pressure on shopping centers management and marketing \& leasing strategy, as not all markets face a flourishing economy. For instance, though the shopping centers domain is at its start in Romania, we can already talk about the failure of major projects that suffered the effects of ignoring some major aspects, correlated with the world economic crises. Such cases are those of: Trident - Sibiu, Armonia Braila, City Mall Bucharest, etc. In the case of City Mall (the biggest bankruptcy case of a mall in Romania), after the shopping center faced insolvency and was sold in 2011 to initial owners for an amount several times less than 2006 acquisition price (17,3 mil. euro, instead of 103,5 mil. Euro), now it is under a reconversion process, being transformed entirely in office spaces.

As conclusion, much of this vacant shopping center space can be absorbed through changes in leasing strategy, by adding more services, more eating-and-drinking establishments, small offices serving local needs, financial institutions, libraries, art galleries/museums and other exhibits are also potential uses. Numerous shopping centers will be evolving into multi-functional business centers (Kircher, 2013). expanding:

E-commerce is turning over the traditional retailing strategies by greatly

- shopping convenience,

- selection,

- affordability. 
In addition to that, m-shopping is enhancing product and price transparency, often to the competitive disadvantage of physical retailers (Nelson A.J. and Billingsley A. 2012).

The connected mobile customer can access information and buy anything, anywhere, anytime.

Through the use of social networking platforms, online purchase is only the formal conclusion of a long process of socialization, communication, and exchange of information that goes beyond the single purchase. S-commerce is for retailers a system of autogenerated services that allow retailers to create (or destroy) the positioning of individual stores (Caboni \& Bruni, 2015) and / or the entire shopping centre.

All these resulted in responses from retailers \& shopping centers, who need to modify the marketing strategies, to remove barriers within the channels and provide cross-channel marketing approach (traditional store, online, and mobile services), such as "order on-line and collect in store," "order in-store, deliver home" "order online, return to store" "virtual showrooms" and other combinations of online and traditional retail activities (Piotrowicz and Cuthbertson, 2014).

The digital revolution has affected the bookstores and the music/video stores, rapidly shifting online. Similarly, electronics stores that have occupied significant amounts of space in shopping centers have also come under pressure. Online groceries increasingly became the "zone" for shoppers unable to find obscure, special or less popular products not stocked on traditional supermarket shelves (Beson et al., 2010).

One clear impact of the digital revolution on retail business marketing is the channel shift of retail sales, away from traditional retailers and towards Internet-only retailers with no physical presence (such as Amazon, eBay, eMAG) and the Internet divisions of "multi-channel" retailers with both virtual stores (e-commerce) and physical stores (such as Wal-Mart).

The trend affects mainly two broad categories: products with a high value relative to shipping costs, and commodity items in which the products are relatively undifferentiated or easily compared online, making price the key determinant in the shopping decision (Nelson and Billingsley, 2012).

In addition, using the Internet and mobile devices (smart phones and tablets) to research goods before making purchases is reducing the traditional store function as a showcase and, consequently, store size (saving on rent, staffing, utilities and other operating expenses), with a final impact on shopping centers management and marketing \& leasing strategy.

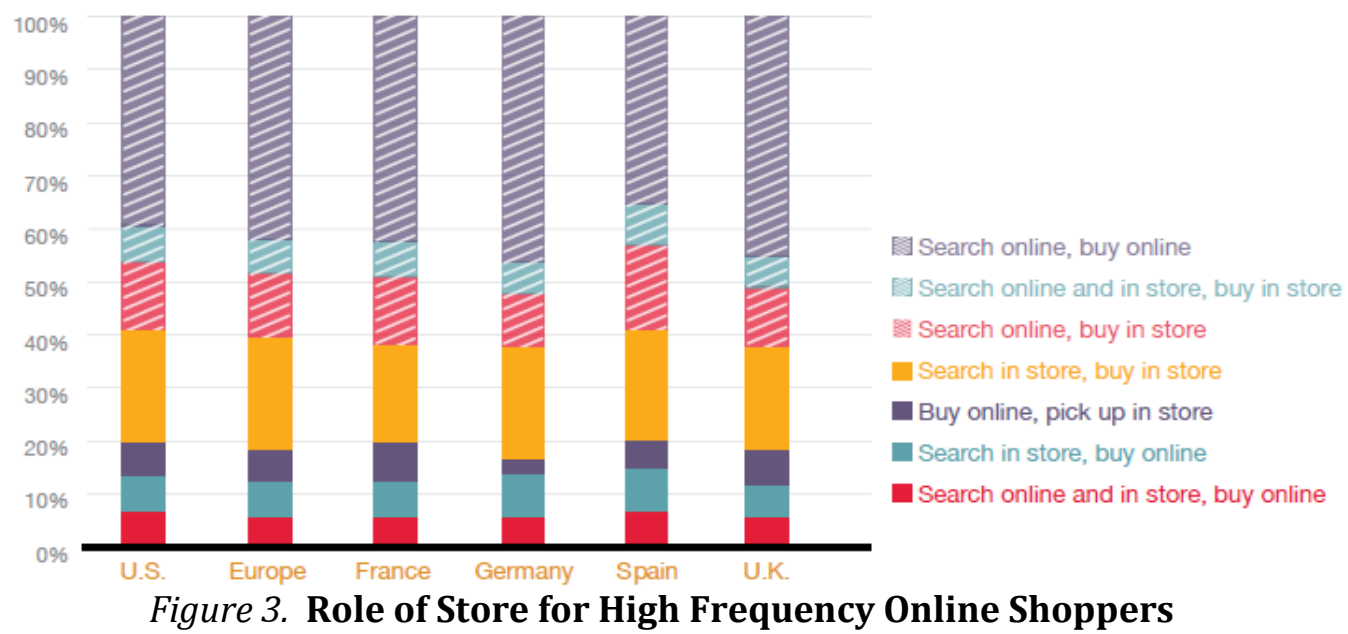

Source ICSC, 2015. 
At the same time, technology is enabling retailers to be more efficient, generating more sales. Retailers often face smaller sales losses when cutting back on the amount and range of merchandise at their stores - no need to stock every color in every size-so long as they can fulfill the delivery promise (Less Holding, More Selling).

Advanced data collection and analytics (existing in the online environment) allow retailers to look at purchase history, product preferences and consumer wish lists to better tailor their offerings towards the clientele. Retailers would be able to predict new collections sizes, styles and color preferences with increasing precision (Benson et al., 2010). These efficiencies will inevitably lead to a revolution in shopping spaces concepts, again with a final impact on shopping centers management.

\section{The digital touch on shopping centers management}

Still, shopping in "traditional" stores represents the most popular route to buy new clothing, as stores provide the "instant gratification of buying the product and experiencing the service" (Blázquez, 2014).

Retailers and shopping centers need to understand that traditional modes of selling must be revitalized with the implementation of new technologies to enhance the possibility of selling products and services and to create strong customer bound.

Especially in fashion case, the key is to think marketing holistically (all communication \& sales channels interrelated) as consumers do; thus, the holistic experience begins before a customer enters the store and continues after the customer leaves (Blázquez, 2014).

One other significant way in which technology will affect the retail industry is that shopping will become a more socially connected, interactive event, pushing retail business to rethink marketing

To reach 50 million people, radio needed 38 years, TV required 13 years, but Facebook managed it in a mere nine months. In the last years there has been a rush into web advertising and social media networks (Thornton, 2010).

Mall owners are all trying their hand at social media, employing Twitter and Facebook to generate shopping-center buzz and touch customers. But it's not as easy as it looks. "New media is a double-edged sword". While it presents easy and cost-effective entry, it also demands constant care and feeding (Boccaccio, 2009).

Search engine optimization techniques are also an essential ingredient in the digital marketing mix. Key search words can be bought to ensure that a center gains prominence near the top of Google's all-important search criteria. Relevance is vital, however.

Big opportunities in digital are often twinned with traps. Multi-channel media approach can often be the most effective (Thornton, 2010).

For example, Amazon implemented order-collection lockers, located in retail shopping centers in the United Kingdom and in 7Eleven stores in the United States, to complement its existing Internet \& mobile (including tablet) shopping channels. Moreover, eBay has used pop-up stores based on instant purchasing using QR (quick response) codes to support its Internet channel (Lewis et al., 2014) - although there were physical items on display, all items were purchased on eBay using mobile devices.

A recent example of this use of technology relates to smartphone applications. "Shopkick" for instance allows shopping-center owners and retailers to reward customers for simply entering a center or a particular store. Incentives can be passed on to shoppers for scanning particular items and trying on clothing. This method to increase visits to retail locations benefits all involved (Benson et al., 2010). 
"Shopkick" is based on the BEACON technology. The portable beacon devices can be hung on a wall or in a machine, and communicate with your phone via Bluetooth signals. The technology is being used to help smartphone users receive special deals as they browse the aisles in a store. Through an app downloaded to shoppers' phones, retailers can send sales alerts to customers as they walk through the door. A survey by mobile marketing company Swirl found that 30 percent of shoppers who received a beacon-triggered deal ended up redeeming that offer in the store, and 73 percent said the promotions increased their likelihood to purchase during their store visit (Fleisher, 2014).

Channel Integration (traditional store, online, and mobile) comes increasingly accessible, though it still represents a logistic challenge, in terms of complete crosschannel integration (as it requires a considerable investment in inventory management and information tracking systems).

Increasingly, customers are also seeking to be able to continue their shopping journey in any place, whether online or in-store. This requires all applications to be integrated and to be capable of identifying individual customers across channels. The linkage of online and in-store customers may be achieved through membership of a loyalty programme by card, online or downloaded mobile app, or increasingly through an opt-in pushed to the customer through the use of Wi-Fi, GPS/mobile and beacontechnology that interacts and tracks web-enabled phones. Digital storefronts and displays are linked to virtual marketing platform using QR (Quick Response) codes and RFID (Radio Frequency Identification) tagging which can inform and entertain the customer on a 24/7 basis. These applications greatly enhance marketing opportunities, with technology and sales assistants both equipped to navigate, direct and assist consumers pre-, during and post-purchase (ICSC, 2015).

Another example is linked to Westfield Group. Westfield Group has set out to simplify the shopping experience in each of its 55 malls throughout the U.S. with the launch of the first-of-its-kind product search feature, available via the free Westfield App. This new feature incorporates the leading edge technology of Google Commerce Search, allowing shoppers to browse the merchandise offerings of retailers located in Westfield shopping centers. Westfield App features include a directory and map for all 55 centers in the United States, special retailer offers, movies show times, shopping hours and the ability to remember the location of a shopper's parked car. (Westfield, 2011).

At Meadowhall, using WiFi you could log on to the center's website to check out the latest offers and events or utilize services such as Voucher Cloud for special offers or trials offered nationally.

By the means of new technology, consumers may have more access to better information about where to find stores in shopping centers, how to efficiently move around shopping centers, where there are sales, and if items they want are in stock or not. The vast amount of information will allow shoppers to compare products and be more knowledgeable about their options from outside a store.

\section{E-technology and the future of shopping experience}

Online and offline experiences can be complementary (Rigby, 2011).

Different customers will value parts of the shopping experience differently, but all are likely to want perfect integration of the digital and the physical - see Table 3. 
Table 1. Advantages of Digital and Physical Shopping

\begin{tabular}{|c|c|}
\hline Advantages of Digital stores & Advantages of Physical stores \\
\hline - $\quad$ Rich product information & - $\quad$ Shopping as an event and an experience \\
\hline - $\quad$ Customer reviews and tips & - $\quad$ Ability to test, try on, or experience products \\
\hline - $\quad$ Editorial content and advice & - $\quad$ Personal help from caring associates \\
\hline - Social engagement and two-way dialogue & - $\quad$ Convenient returns \\
\hline - $\quad$ Broadest selection & - Instant access to products \\
\hline - $\quad$ Convenient and fast checkout & - $\quad$ Help with initial setup or ongoing repairs \\
\hline - $\quad$ Price comparison and special deals & - Instant gratification of all senses \\
\hline $\begin{array}{l}\text { - Convenience of anything, anytime, } \\
\text { anywhere access }\end{array}$ & - $\quad$ Edited assortment \\
\hline
\end{tabular}

PICBE $\mid 757$

Source: Rigby, 2011.

Retail business and shopping centers as key players need to capitalize on physical stores advantages ("Shopping as an event and an experience"), but to provide also content for the digital aspects, to satisfy the need of complete information, availability and convenience of nowadays shopper.

The personal experience (feel, see, try, touch, taste) remains the key incentive that drives shoppers into shopping centers \& physical stores and should be the focus of nowadays marketing strategies in retail / shopping centers management.

For example, there's one time that nothing can meet the emotional needs of the shopper as well as the tangible merchandise of bricks-and-mortar store, and that's during the holiday season (Kramer, 2009).

Also, clothing is considered to be a high involvement product category, related to personal ego and products that need to be seen, felt, touched, and tried on because they are difficult to evaluate.

A multi-channel marketing approach dramatically strengthens the link between the online shopper and the bricks-and-mortar store or shopping center.

"While e-stores cannot replace the personalized service, fitting, or tactual experience of buying clothes, the potential of greater, lower-cost, higher-margin online sales is a powerful card, and using websites to put catalogue range previews of current collections can actually be a great stimulus to brick-and-mortar" traditional shops- says Simon Wall of Identity Solutions, the creator of Niche Fashion Technology (Fielding, 2009).

\section{Conclusions}

E-commerce is transforming both consumer behavior and retailing business models and marketing by greatly expanding shopping convenience, selection and affordability, and increasing the media exposure, via digital communication channels.

The use of new technologies provides consumers with a more stimulating way of interacting, better adapted to nowadays needs and lifestyle.

Still the personal experience remains the key incentive that drives shoppers into shopping centers \& physical stores.

The shopping centers management \& practitioners have the difficult job of "listening" and consolidating the management of shopping centers for the consumer needs, needs that are in constant change and adaptation, becoming more and more complex along with technology evolution and the growth of globalization and sophistication level.

Retail business and shopping centers as key players need to capitalize on physical stores advantages ("Shopping as an event and an experience"), but to provide also content for the digital aspects, to satisfy the need of complete information, availability and convenience of nowadays shopper. 
The personal experience (feel, see, try, touch, taste) remains the key incentive that drives shoppers into shopping centers \& physical stores and should be the focus of nowadays marketing strategies.

\section{References}

Benson, A., Panfel, M., Tubridy, M. (2010). U.S. Shopping Centers: The Shape of Things to Come: Ongoing and Recent Influences Likely to Alter the Industry in the Next Decade, Retail Property Insights, 17(3), 25-34.

Birner, K. (2015). One click to empowerment? Opportunities and challenges for labour in the global value chain of e-commerce, International Journal of Labour Research, 7(1-2), 55-73.

Blázquez, M. (2014). Fashion Shopping in Multichannel Retail: The Role of Technology in Enhancing the Customer Experience. International Journal of Electronic Commerce, 18(4), 97-116.

Boccaccio, K. (2009). Focus on: Shopping Center Marketing Trends, December, http://www.chainstoreage.com/article/focus-shopping-center-marketingtrends.

Caboni, F. \& Bruni, R. (2015). On-line Commerce and Town Centre Retailers' Experience, International Journal of Marketing Studies, 7(6).

Fielding, M. (2009). Channel surfing. New Zealand Apparel. 42(2), 12-13.

Fleisher, C. (2014). Beacons track shoppers' smartphones amid retailers' aisles. Pittsburgh Tribune Review (PA).

Kircher, H.J. (2013). E-commerce: Weighing the Impact on Bricks and Mortar. Retail Property Insights, 20(2), 11-13.

Kramer, P. (2009). Internet helps outlets keep competitive edge Value Retail News 27, no. 9: 18 ICSC NEWS. SCTWeek, 10/18/2013, 18, 42.

ICSC. (2015), Exploring New Leasing Models in an OMNI-CHANNEL WORLD.

Lewis, J., Whysall, P., \& Foster, C. (2014). Drivers and Technology-Related Obstacles in Moving to Multichannel Retailing. International Journal Of Electronic Commerce, 18(4), 43-68. doi:10.2753/JEC1086-4415180402.

Nelson, A.J., Billingsley, A. (2012). The New Urban Frontier, Retail Property Insights 19, no. 3 (September 2012): 24-30.

Piotrowicz, W., Cuthbertson, R. (2014). Introduction to the Special Issue Information Technology in Retail: Toward Omnichannel Retailing. International Journal of Electronic Commerce, 8(4), 5-16.

Reynar, A., Phillips J., Heumann S., 2010, New Technologies Drive CPG Media Mix Optimization, Journal of Advertising Research, December 2010, DOI:10.2501/S0021849910091567.

Rigby, D. (2011). The Future of Shopping, Harvard Business Review [serial online]. December 2011, 89 (12):64-75.

Thornton, A. (2010). Marketing measures up, Estates Gazette, October 31, 2010; 54-57.

Westfield G., 2011, Westfield Simplifies In-Mall Shopping with New Product Search Feature on Free Westfield Mobile App., Business Wire (English) [serial online], August 2011. 